FRANK DE LEEUW

Bureau of Economic Analysis

MICHAEL J. MC KELVEY

Bureau of Economic Analysis

\title{
Price Expectations of Business Firms
}

Price expeCtations by business are an integral part of the process by which inflation maintains or alters its momentum. Empirical studies of price expectations in the United States, however, have relied mainly on surveys of professional forecasters or of households. Useful though these studies are, the absence of studies of price expectations by businessmen has been a serious omission.

Since 1970 the year-end surveys of business expenditures on plant and equipment conducted by the Bureau of Economic Analysis have included a question about price expectations. The question is asked separately for prices of capital goods purchased and prices of goods and services sold. The question in the survey conducted at the end of 1980, essentially the same as in earlier years, was: "What are your best estimates of average price changes from 1979 to 1980 and from 1980 to 1981? (Approximations are acceptable.)" The survey included a box for entering perceptions of the past (1979-80) price change and one for entering expectations for the future (1980-81) change (both in percent). The responses to the question on capital goods prices for major industry aggregates have been published regularly in January issues of Survey of Current Business.

In recent years approximately 5,000 companies have responded to each year-end plant and equipment survey. The typical respondent is a company staff member in either the office of the comptroller or of the chief accountant. Not all respondents answer the questions on prices; approximately 3,200 firms respond to the question on prices of capital 
goods and slightly fewer answer the sales price question. Of these firms, about 1,200 are in manufacturing industries; 300 are in mining and construction; 600 are in trade industries; and 1,100 are in the rest of the economy. The industry price changes reported below are weighted averages of company responses. Weights reflect the survey's sampling fraction for three size groupings in each industry, and the level of capital spending of individual companies (in aggregating capital goods price changes) and sales (in aggregating sales price changes).

Little is known about the quality of the responses to the price question. The responses to the inquiry about past price changes at the two-digit industry level generally correlate highly with percentage changes derived from official price indexes for the same industries. However, it is hard to imagine that respondents know as much about price changes in their companies, especially in the case of diversified firms, as they do about capital expenditures, sales, or other income-statement items.

In this paper we describe and analyze ten years of observations of the responses on sales price expectations for seventeen industries and capital goods price expectations for twenty-three industries. We first present data highlights, including statistics on errors in expectations by industry and by year. We then report on some standard tests of the rational expectations hypothesis and on tests of other hypotheses about expectations. It is our hope that other students of price expectations will be stimulated to use and analyze the data further.

\section{Data Highlights}

Business expectations about price changes have been rising irregularly since 1970. As table 1 shows, aggregate expectations about sales prices began slightly below 4 percent in 1971, fell slightly during the period of 1972-73 controls, rose rapidly to more than 8 percent following the price shocks of 1973 and 1974, and then declined in 1976 to just over 6 percent. ${ }^{1}$ They stabilized near 6 percent for several years, but in 1980 resumed their rise and exceeded 10 percent for the first time in 1981. Expected changes in capital goods prices were greater than in sales prices

1. The expected price change for 1971 , for example, refers to the survey results collected at the end of 1970; see note b of table 1 . 
Table 1. Expected and Reported Percent Changes in Prices, Nonfarm Business Sector, 1971-81

\begin{tabular}{|c|c|c|c|c|}
\hline \multirow[b]{2}{*}{ Year } & \multicolumn{2}{|c|}{ Prices of goods and services sold ${ }^{\mathrm{a}}$} & \multicolumn{2}{|c|}{ Prices of capital goods purchased } \\
\hline & Expected $^{\mathrm{b}}$ & Reported $^{\mathrm{c}}$ & Expected $^{\mathrm{b}}$ & Reported $^{\mathrm{c}}$ \\
\hline 1971 & 3.9 & 2.1 & 6.6 & 6.6 \\
\hline 1972 & 3.0 & 2.5 & 5.1 & 5.7 \\
\hline 1973 & 2.4 & 5.7 & 5.4 & 7.6 \\
\hline 1974 & 5.3 & 16.0 & 8.3 & 15.0 \\
\hline 1975 & 8.8 & 8.9 & 12.9 & 12.2 \\
\hline 1976 & 6.1 & 5.9 & 9.7 & 8.3 \\
\hline 1977 & 6.1 & 6.3 & 7.9 & 7.8 \\
\hline 1978 & 6.1 & 6.6 & 7.9 & 8.0 \\
\hline 1979 & 6.3 & 9.4 & 8.1 & 9.6 \\
\hline 1980 & 8.7 & 12.1 & 9.9 & 10.7 \\
\hline 1981 & 10.4 & n.a. & 10.8 & n.a. \\
\hline
\end{tabular}

Source: Unpublished data from the U.S. Department of Commerce, Bureau of Economic Analysis. n.a. Not available.

a. The first two columns represent an aggregate of sales prices for manufacturing and utilities; other industries are omitted because of lack of sufficient data. The reported price changes for sales differ from changes in widely used measures of aggregate price change (for example, the change in the GNP deflator) primarily because of these omissions and because primary product prices receive more weight in the calculation of sales prices than they do in the GNP deflator.

b. The expected price change for year $t$ (for example, 1971) is the percent change in prices from year $t-1$ (1970) to year $t$ expected at the end of year $t-1$.

c. The reported price change for year $t$ is the percent change in prices from year $t-1$ to year $t$ reported at the end of year $t$.

throughout the period but showed a similar pattern of change over time. The table suggests a clear influence of recent actual inflationary behavior on expectations for the year ahead.

Errors in expectations vary greatly by industry and by year. As table 2 shows, root-mean-square errors in sales price expectations by industry range from a little more than 1 percentage point for aircraft to slightly more than 20 points for petroleum. By year, the range (based on seventeen industries for each year) is from less than 1 percentage point in 1972 and 1978 to more than 16 points in 1974 . The errors tend to be smaller for capital goods prices than for sales prices.

The errors in expectations tend to be smaller than the errors that would result from simply assuming that the most recently observed rate of price increase will continue; but this improvement over a "samechange" assumption does not hold for every industry group or every year. Theil's $U$-statistic, shown in table 2 , registers zero if there are no errors in expectations and 100 if the expected price change is always 
Table 2. Measures of Accuracy of Price Expectations, by Industry and Yeara

\begin{tabular}{|c|c|c|c|c|}
\hline \multirow[b]{2}{*}{ Industry } & \multicolumn{2}{|c|}{ Sales prices } & \multicolumn{2}{|c|}{ Capital goods prices } \\
\hline & $\begin{array}{l}\text { Root-mean- } \\
\text { square error }\end{array}$ & $\boldsymbol{U}$ & $\begin{array}{l}\text { Root-mean- } \\
\text { square error }\end{array}$ & $U$ \\
\hline All industries & 3.84 & 77 & 2.35 & 80 \\
\hline Manufacturing & 3.79 & 86 & 2.61 & 79 \\
\hline Durable goods & 2.53 & 79 & 2.36 & 80 \\
\hline Stone, clay, glass & 2.76 & 80 & 3.24 & 84 \\
\hline Blast furnaces & 6.31 & 78 & 1.71 & 105 \\
\hline Nonferrous metals & 4.71 & 54 & 3.60 & 85 \\
\hline Machinery except electrical & 1.91 & 79 & 2.25 & 85 \\
\hline Electrical machinery & 2.37 & 86 & 2.02 & 77 \\
\hline Motor vehicles & 1.91 & 96 & 2.46 & 79 \\
\hline Aircraft & 1.14 & 87 & 2.94 & 87 \\
\hline Other durables & 2.27 & 79 & 2.44 & 81 \\
\hline Nondurable goods & 5.27 & 90 & 2.94 & 80 \\
\hline Food including beverage & 4.40 & 100 & 2.27 & 85 \\
\hline Textiles & 1.61 & 58 & 1.75 & 88 \\
\hline Paper & 4.41 & 77 & 3.19 & 82 \\
\hline Chemicals & 4.21 & 81 & 2.81 & 79 \\
\hline Petroleum & 20.05 & 77 & 2.82 & 80 \\
\hline Rubber & 3.65 & 75 & 2.65 & 78 \\
\hline Other nondurables & 1.27 & 82 & 1.67 & 73 \\
\hline Nonmanufacturing & n.a. & n.a. & 2.15 & 78 \\
\hline Mining & n.a. & n.a. & 6.06 & 83 \\
\hline Railroad & n.a. & n.a. & 5.70 & 84 \\
\hline Air transportation & n.a. & n.a. & 2.01 & 84 \\
\hline Other transportation & n.a. & n.a. & 3.44 & 86 \\
\hline Electric utilities & 6.60 & 88 & 2.06 & 72 \\
\hline Gas and other utilities & 3.71 & 102 & 3.51 & 88 \\
\hline Communication & n.a. & n.a. & 1.45 & 78 \\
\hline Commercial and other & n.a. & n.a. & 2.29 & 84 \\
\hline
\end{tabular}

equal to the most recently observed price change. By industry, the $U$ statistics indicate moderate improvement over a same-change assumption; for sales prices, the statistics for twelve of the seventeen industries lie between 70 and 90; for capital goods prices, the statistics for every industry except one (blast furnaces) are between 70 and 90 . By year, there is much more variation; for both sales and capital goods, expected price changes in 1972, 1975, and 1976 were decidedly more accurate than a projection of the most recently observed price change. In 1974 and 1979, however, there was little difference in accuracy between the two methods, 
Table 2 (continued)

\begin{tabular}{cccccc}
\hline & \multicolumn{2}{c}{ Sales prices } & & \multicolumn{2}{c}{ Capital goods prices } \\
\cline { 2 - 3 } \cline { 5 - 6 } Year & $\begin{array}{c}\text { Root-mean- } \\
\text { square error }\end{array}$ & $U$ & & $\begin{array}{c}\text { Root-mean- } \\
\text { square error }\end{array}$ & $U$ \\
\hline 1971 & 1.59 & 64 & & 0.84 & 92 \\
1972 & 0.80 & 52 & & 1.06 & 71 \\
1973 & 3.85 & 102 & & 2.62 & 107 \\
1974 & 16.65 & 97 & & 8.34 & 93 \\
1975 & 3.03 & 20 & & 1.89 & 46 \\
1976 & 1.29 & 31 & & 2.02 & 43 \\
1977 & 1.25 & 96 & & 0.76 & 71 \\
1978 & 0.84 & 53 & & 1.08 & 119 \\
1979 & 4.99 & 101 & & 2.17 & 95 \\
1980 & 5.74 & 153 & & 1.23 & 101 \\
\hline
\end{tabular}

Source: Calculations by the authors based on data from the Bureau of Economic Analysis.

n.a. Not available.

a. Root-mean-square error $=\left[\sum_{i=1}^{N}\left(A_{i}-E_{i}\right)^{2} / N\right]^{1 / 2} \quad U=100\left[\sum_{i=1}^{N}\left(A_{i}-E_{i}\right)^{2} / \sum_{i=1}^{N}\left(A_{i}-A_{j}\right)^{2}\right]^{1 / 2}$ where

$A=$ reported actual rate of change in prices (percent)

$E=$ expected rate of change in prices (percent)

$N=$ number of observations

$i=i$ th observation

$j=$ observation for the previous year for industry represented in $i$ th observation.

The statistics for each industry are based on annual observations from 1971 to 1980 . The statistics for each year are based on observations of seventeen industries for sales prices and on twenty-three industries for capital goods prices, weighted equally. The sales price statistics for "all industries" refer to an aggregate of manufacturing and utilities; other industries are omitted because of lack of sufficient data.

The root-mean-square errors are measured in percentage points; for example, 3.0 is a mean error of 3 percentage points. The $U$-statistics are measured in index points; thus 80 is a mean error equal to 80 percent of the mean error associated with assuming the same price change as the preceding year.

while in 1973 and 1980 reported expectations proved less accurate than a projection of the most recent change.

\section{Tests of the Rational Expectations Hypothesis}

An important analytical use of the data is to test the rational expectations hypothesis about price change - that is, the hypothesis that the differences between expected and actual rates of price change do not exhibit any systematic pattern, but instead constitute a random variable with zero mean. It is this hypothesis, in combination with some special assumptions about the nature of other macroeconomic relations, that can lead to the conclusion that inflation rates need not have any continuity or 
momentum but can be altered drastically with little or no impact on real output. $^{2}$

Table 3 shows the results of two widely employed tests of the rational expectations hypothesis applied to the pooled industry-time series data of the Bureau of Economic Analysis. The first is a test of whether, in a linear regression of actual price change on expected price change, the coefficient of expected price change differs significantly from 1.0 and the constant term differs significantly from zero. This is a test for bias in expectations. The second is a test of whether, in a regression of actual price change on expected price change and other variables widely known at the time expectations were reported, the latter variables have significant coefficients. This is a test for the efficiency of expectations; if actual price change is related to these other variables as well as to the reported expectations, reported expectations must not have made efficient use of all widely known information.

The rational expectations hypothesis fares poorly in these tests. The first two rows of table 3 report the results of the bias test for sales prices and capital goods prices for the 1971-80 period. The next two rows show what happens in the bias test when we omit observations for 1974, the year of the largest errors in expectations. The grounds for omitting 1974 might be that, although the extraordinary events that influenced prices in 1974 (in particular, the first OPEC price increase and the end of U.S. price controls) might not distort test results in a very long sample of years, they are likely to do so in a span as short as ten years. ${ }^{3}$ The last column shows an $F$-test of the joint hypothesis of a constant term of zero and a coefficient of 1.0 on the expectations variable. An interesting feature of the results is that the coefficient of expected change in sales prices is greater than 1.0 while the coefficient of expected change in capital goods

2. A recent review of the rational expectations hypothesis and its implications appears in Bennett T. McCallum, "Rational Expectations and Macroeconomic Stabilization Policy: An Overview," Journal of Money, Credit, and Banking, vol. 12 (November 1980), pt. 2, pp. 716-46.

3. There is also a statistical basis for omitting 1974. An F-test of the hypothesis underlying the pooled regressions, namely that coefficients in a regression of actual on expected price changes are equal for all industries, indicated that for sales prices the hypothesis could be rejected with 95 percent confidence when 1974 was included but not when 1974 was omitted. The hypothesis could not be rejected for capital goods prices, with or without 1974. 
prices is less than 1.0. However, for both sets of prices, with or without 1974 , the $F$-ratios in the last column of the table indicate, with more than 99 percent confidence, that the hypothesis of unbiased errors must be rejected.

The fifth through eighth rows report the results of tests for efficiencynamely, tests for the significance of primary-product capacity utilization and of changes in money supply when they are included in a regression of actual price change on expected price change. Capacity utilization and changes in money supply are the only two variables we tested in our analysis of the efficiency of expectations, although they are clearly only two of a host of variables that might influence actual and expected price changes.

The capacity-utilization variable for capital goods prices in every industry was specified as capacity utilization for durable goods materials in the third quarter of the year at the end of which the price expectations were reported. This was also the capacity-utilization variable for sales prices in durable goods industries. For the textiles, paper, chemicals, rubber, and "other nondurables" industries the utilization variable for sales price was capacity utilization for nondurable goods materials in the third quarter of the year at the end of which the price expectations were reported. For other nondurable goods industries-food and beverage, petroleum, electric utilities, and gas and other utilities-a cyclical effect of capacity utilization appeared unlikely. A dummy variable, equal to 1.0 for these industries and zero for the others, was used to prevent the capacity utilization variables from disturbing the estimates of other coefficients.

The money supply variable we used was percent change from the previous year in M1 before the 1980 revision, the money variable most widely publicized during the $1970 \mathrm{~s}$. Because the variable is used with lags, we did not need to choose among the new concepts introduced in 1980.

In three of the four equations including lagged capacity utilization (equations 3-5, 3-7, 3-11) the $t$-ratios for utilization are above 2.0. Even in the fourth (equation 3-9), while the individual coefficients for capacity utilization and for the dummy variable used in food, petroleum, and utilities have $t$-ratios below 2.0, a test of their joint significance indicates with greater than 95 percent confidence that jointly they have a positive 


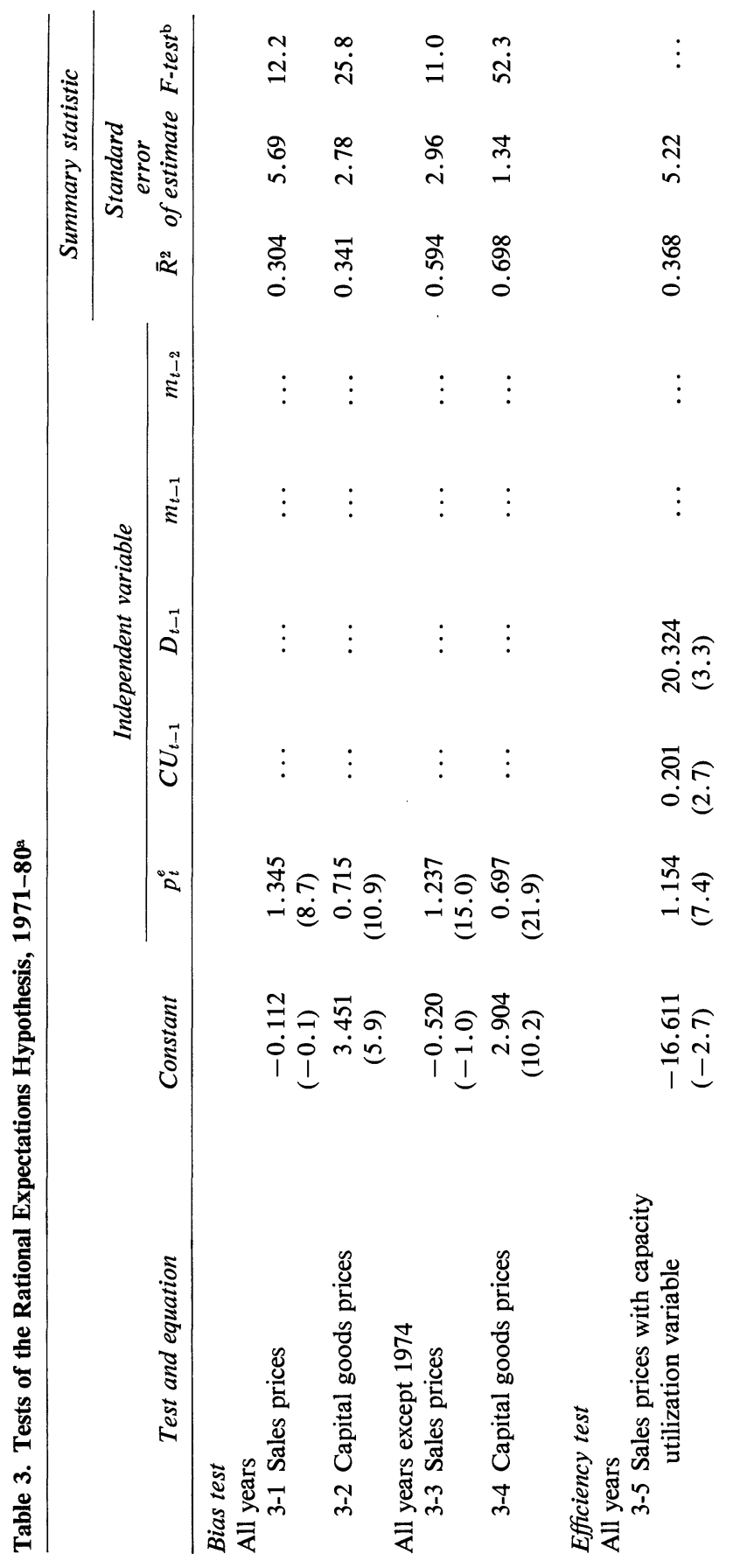




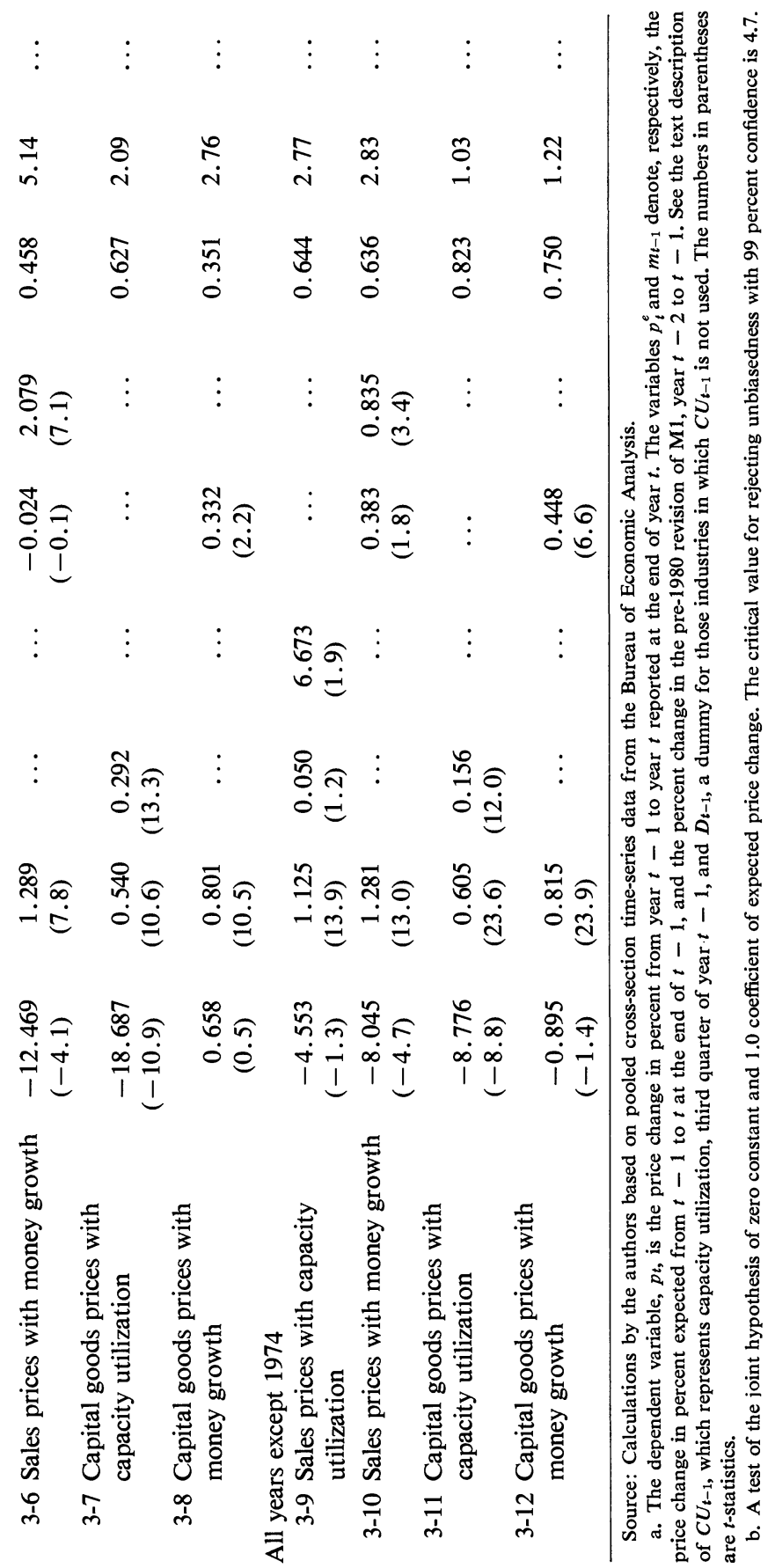


relation to actual price changes. The rate of growth of the money supply lagged two years is significant for sales prices, and the rate of growth of the money supply lagged one year is significant for capital goods prices. (Money supply growth lagged two years was never significant for capital goods prices and is not shown.) Thus these efficiency tests as well as the bias tests suggest that the hypothesis of rational expectations did not apply to price expectations by U.S. businesses in the 1970s, even if 1974 is excluded.

Tests of the kind reported in table 3 raise a number of econometric problems. One of them is errors in variables; respondents are likely to under- or overstate both expected price change and reported price change for a variety of reasons. We believe that by basing our tests on industry aggregates rather than on observations for individual firms, the importance of errors in variables is greatly reduced. Industry aggregates are a form of grouped data in which much of the under- and overstatement by individual firms is likely to cancel.

A second econometric problem is that the pooled regression results reflect both changes over time and differences among industries; but for macroeconomic analysis we are interested mainly in changes over time. To focus the results on the time dimension, we calculated regressions including industry dummy variables. Almost none of the dummy variables was significant, and none of the conclusions based on the reported regressions was altered by the results including the dummy variables.

A third problem is that because errors in expectations tend to have the same movements over time in many industries (for example, price expectations were too low in 1974 for almost every industry), the assumption of zero covariances among error terms is suspect. To address this problem, we applied a variance-components model to the first two regressions reported in table 3 . Again, none of the conclusions was changed by this procedure. ${ }^{4}$

4. The procedure we used is described in Marc Nerlove, "A Note on Error Components Models," Econometrica, vol. 39 (March 1971), pp. 383-96, and Wayne A. Fuller and George E. Battese, "Estimation of Linear Models with Crossed-Error Structure," Journal of Econometrics, vol. 2 (May 1974), pp. 67-78. The result for the first equation for sales (3-1) was $p_{t}=-1.909+1.649 p_{t}^{e}$. For the second equation (3-2), the result was $(-1.1) \quad(8.5)$

$p_{t}=5.248+0.502 p_{t}^{e}$. The null hypothesis of zero constant and slope coefficient of 1.0 (5.2) (7.1)

continues to be rejected in both cases. 


\section{Tests of the Error-Learning Hypothesis}

Most empirical and many theoretical macroeconomic models employ the hypothesis of adaptive expectations - that is, the hypothesis that current price expectations reflect a distributed lag of the past actual behavior of prices. The hypothesis of adaptive expectations supports the conclusion that past inflation rates have strong momentum, and that attempts to reduce current-dollar output will initially have a heavy impact on real output rather than on prices.

A simple form of the hypothesis of adaptive expectations is the errorlearning model. ${ }^{5}$ According to this model, expectations about an economic variable are revised in light of the most recently observed error. Thus if $p_{t}$ is the actual percent change in prices in period $t$, and $p_{t}^{e}$ is the percent change in prices that was expected as of the end of the previous period $t-1$, the error-learning hypothesis states that the change in expected value from $t-1$ to $t,\left(p_{t}^{e}-p_{t-1}^{e}\right)$, depends on the error made in the previous period, $\left(p_{t-1}-p_{t-1}^{e}\right)$. In linear form, the hypothesis is

$$
p_{t}^{e}-p_{t-1}^{e}=\alpha\left(p_{t-1}-p_{t-1}^{e}\right) \quad 1>\alpha>0,
$$

or, equivalently,

$$
p_{t}^{e}=\alpha p_{t-1}+(1-\alpha) p_{t-1}^{e},
$$

which implies that $p_{t}^{e}$ depends ultimately on a distributed lag of past values of $p_{t}$, with geometrically declining weights. As equation 2 makes clear, the hypothesis suggests that expected price changes are related positively to both the previous actual change and to the previous expected change, and that the sum of the coefficients of these two explanatory variables is 1.0.

The error-learning model receives only limited support from tests using data from the Bureau of Economic Analysis. ${ }^{6}$ As shown in table 4,

5. An early and influential statement of this hypothesis appears in Philip Cagan, "The Monetary Dynamics of Hyperinflation," in Milton Friedman, ed., Studies in the Quantity Theory of Money (University of Chicago Press, 1956), p. 37.

6. Edward J. Kane and Burton G. Malkiel reached a similar conclusion in "Autoregressive and Nonautoregressive Elements in Cross-Section Forecasts of Inflation," Econometrica, vol. 44 (January 1976); pp. 1-16. Using cross-section data from a panel of institutional investors, Kane and Malkiel found that while the errorlearning mechanism explained a proportion of the variance in expected price changes, there was evidence that other variables were also important. 
Table 4. Tests of the Error-Learning Model, 1971-80a

\begin{tabular}{|c|c|c|c|c|c|c|}
\hline \multirow[b]{3}{*}{ Test } & \multirow[b]{3}{*}{ Constant } & & & \multicolumn{3}{|c|}{ Summary statistic } \\
\hline & & \multicolumn{2}{|c|}{ Independent variable ${ }^{\mathrm{a}}$} & \multirow{2}{*}{\multicolumn{2}{|c|}{$\begin{array}{c}\text { Standard } \\
\text { error } \\
\text { of estimate }\end{array}$}} & \multirow[b]{2}{*}{$t$-test ${ }^{\mathrm{b}}$} \\
\hline & & $p_{t-1}$ & $p_{t-1}^{e}$ & & & \\
\hline \multicolumn{7}{|l|}{ All years } \\
\hline Sales prices & $\begin{array}{l}2.169 \\
(5.6)\end{array}$ & $\begin{array}{l}0.153 \\
(5.2)\end{array}$ & $\begin{array}{l}0.537 \\
(7.5)\end{array}$ & 0.514 & 2.19 & 5.11 \\
\hline Capital goods prices & $\begin{array}{l}1.971 \\
(7.7)\end{array}$ & $\begin{array}{c}0.792 \\
(29.2)\end{array}$ & $\begin{array}{l}-0.076 \\
(-2.3)\end{array}$ & 0.838 & 1.14 & 10.19 \\
\hline \multicolumn{7}{|l|}{ All years except 1975} \\
\hline Sales prices & $\begin{array}{l}1.958 \\
(7.2)\end{array}$ & $\begin{array}{c}0.531 \\
(13.2)\end{array}$ & $\begin{array}{l}0.126 \\
(2.0)\end{array}$ & 0.779 & 1.47 & 8.15 \\
\hline Capital goods prices & $\begin{array}{l}1.322 \\
(4.9)\end{array}$ & $\begin{array}{l}1.029 \\
(18.9)\end{array}$ & $\begin{array}{l}-0.239 \\
(-5.3)\end{array}$ & 0.779 & 1.05 & 7.05 \\
\hline
\end{tabular}

Source: Same as table 3.

a. The dependent variable, $p_{t}^{e}$, is the expected price change in percent from year $t-1$ to year $t$ reported at the end of year $t-1$. The explanatory variables $p_{t-1}$ and $p_{t-1}^{e}$ are, respectively, actual price change in percent from $t-2$ to $t-1$ reported at the end of $t-1$, and the expected price change in percent from $t-2$ to $t-1$ reported at the end of $t-2$. The numbers in parentheses are $t$-statistics.

b. A test of the hypothesis that the sum of the coefficients of $p_{t-1}$ and $p_{t-1}^{e}$ equals 1.0. The critical value for rejecting the hypothesis with 99 percent confidence is 2.58 .

actual price change for the preceding year has a positive and highly significant coefficient in all cases. Lagged price expectations have a positive and significant coefficient for sales prices, but-contrary to hypothesishave a negative and significant coefficient for capital goods prices. Furthermore, the $t$-test reported in the last column of the table indicates that the sum of the coefficients for the two variables is significantly below 1.0 in all cases. ${ }^{7}$

Results are shown for all years and for all years excluding 1975 . When expected price change rather than actual price change is the dependent variable, it is 1975 rather than 1974 that contains the largest errors for sales prices (but not for capital goods prices). Very large actual price changes in 1974 (far above expectations) were followed by fairly moderate upward revisions of sales price expectations for 1975, presumably because businesses recognized the influence of special factors affecting 1974. If one concedes that expectations for 1975 did not follow an adaptive scheme, how did such a scheme fare in years other than 1975? This

7. As in the case of the rational expectations hypothesis, tests including industry dummy variables do not change any of the conclusions and are not reported here. 
is the question that is answered by the rows of results that exclude 1975: the influence of lagged actual price change is much greater, and that of lagged expectations smaller (larger negative values in the case of capital goods prices). The sum of the two coefficients does not change greatly.

\section{Tests of an Augmented Error-Learning Model}

Following the lead of other investigators, we tested an error-learning model augmented by three other explanatory variables: change in the rate of price increase from two years ago to one year ago, lagged capacity utilization (together with the dummy variables for individual industries described earlier), and lagged rates of change in the money supply one year ago and two years ago. ${ }^{8}$ Results are shown in table 5 .

The three variables are of interest because they all have implications for the cost (in lost output) of reducing inflation. A positive coefficient for the variable denoting change in price increase implies that reductions in rates of price increase themselves develop a momentum that speeds up the process of moving to a lower target rate of inflation (accelerations of price increases have the opposite effect). Adding this variable takes a step toward the complex dynamic models of adaptive expectations that have been tested in recent studies. ${ }^{9}$ A positive coefficient for capacity utilization implies that a recession will lower price expectations directly as well as indirectly through its effect on current market prices. A positive coefficient for changes in the money supply implies that reduced money growth will lower price expectations directly in addition to its influence on the supply of credit.

Clearly these three variables are only a sample of the possible ways of representing price dynamics, cyclical variations in resource utilization, and the effects of policy announcements. To mention just two omissions, there is no representation of fiscal policy and no attempt to measure a "policy credibility" effect.

8. The last two of these also appear in tests of the rational expectations hypothesis reported in table 3 . In that table current reported price change is the dependent variable, while in table 5 expected price change is the dependent variable and lagged reported price change is one of the independent variables.

9. See, for example, Rodney L. Jacobs and Robert A. Jones, "Price Expectations in the United States, 1947-75," American Economic Review, vol. 70 (June 1980), pp. 267-77. 


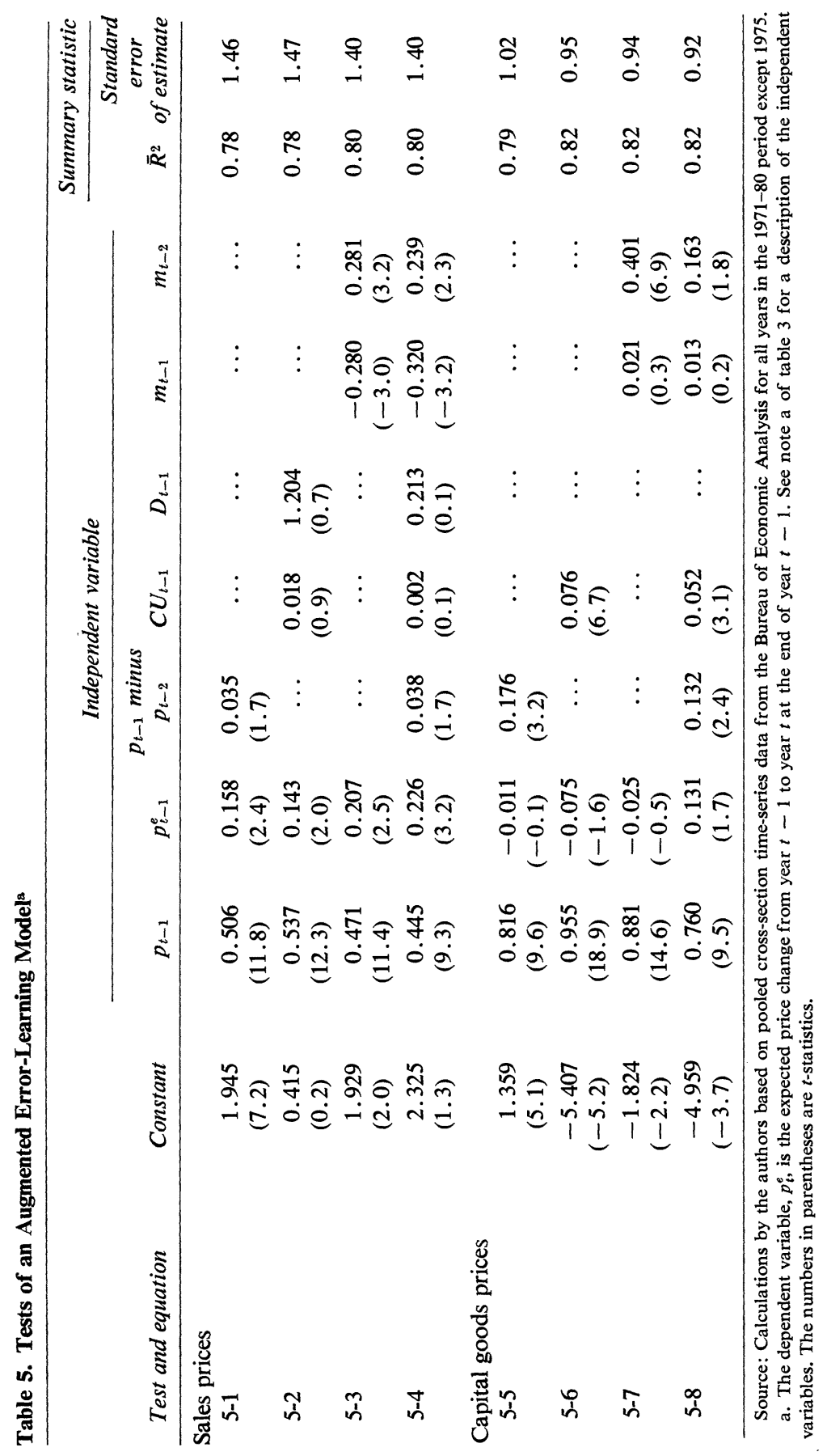


Coefficients of the three additional variables we tested are significant for capital goods prices but not for sales prices. To conserve space, the results in table 5 are limited to those that exclude 1975. For sales prices, the only significant additional variables are lagged changes in the money supply; but coefficients of the variable denoting a change one year ago and the variable of change two years ago have opposite signs with a net impact close to zero. For capital goods prices, however, not only do all three variables have significant positive impacts, but the puzzling significant negative coefficient of lagged price expectations in the errorlearning model becomes insignificant (and, in equation 5-8, positive) in the presence of these additional variables. Even for capital goods prices, however, the additional variables do not greatly reduce the unexplained variation in price expectations.

In sum, our initial analysis of price expectation data from the Bureau of Economic Analysis does not support the rational expectations hypothesis, gives only limited support to a simple error-learning model, and provides mixed results for an augmented error-learning model including past changes in the rate of increase of prices, capacity utilization, and changes in money supply. One positive finding is a strong association between expected price change and the most recently observed price change.

\section{Discussion}

A DETAILED EXAMINATION of expectations by firms, rather than their expectations averaged to the industry level, was suggested by Christopher Sims to provide a better test of rationality and other characteristics of forecasts. There might be bias in the regressions by industry because, at the time they forecast, firms do not know the industry averages that are treated as "known" in interpreting the industry regressions. On the basis of similar studies on sales expectations, Michael Lovell conjectured that disaggregating the analysis to the firm level would make the results depart even further from the predictions of the rational expectations model. Stanley Fischer added that a disaggregated study of the Michigan survey data revealed far less rationality than the averages from that survey implied. At times in the past decade, about one-fourth of the sample 
expected no change in prices. Robert Hall noted that, in addition to attributing industry knowledge to the firm, the test for rationality presumed the forecasters had knowledge of a relation between capacity utilization and forecast errors that may not have existed at the time the forecasts were made. Benjamin Friedman agreed in principle with Hall, but did not believe the objection was forceful because capacity utilization was a well-known variable whose relation to pricing had been discussed for a long time before the sample period. Michael McKelvey added that estimating a rolling regression made little difference to the findings.

Friedman observed that the present results were in line with studies of other economic variables, such as interest rates or wage expectations, which quite consistently have rejected the rationality hypothesis. Robert Gordon added that the results supported the importance of backwardlooking expectations formation. There is inertia in the economy's adjustment process not simply because of a wage-wage spiral based on catch-up, but also because price expectations are based upon extrapolation of recent experience.

Several panel members discussed the puzzling differences in performance of expectations in the sales and capital goods equations. Franco Modigliani noted that capital goods prices are predicted better than sales prices and speculated that it might be because they refer to deliveries already contracted for. McKelvey noted capital goods prices might simply be easier to forecast because their variance is smaller. Robin Marris reasoned there might be a downward bias on sales prices expectations, as compared with input prices, because people do not like to say their own prices will be increased. William Brainard explained that the downward bias in sales expectations could reflect the fact that firms reporting their own price increases are not fully aware of the (correlated) pricing decisions of other firms. The fact that the competition is also raising prices leads these reporting firms to increase their own prices more than they had expected. Although a parallel argument would help explain the upward bias in capital goods expectations, Brainard found it less plausible. James Tobin noted that both biases are consistent with forecasters building in a risk premium by making predictions less favorable to the firm than their expectations. 